\title{
Karpal Tünel Sendromu Semptomları ile Başvuran Hastalarda Fibromiyalji Sıklığı*
}

\author{
Şüheda ÖZÇAKIR
}

Bursa Uludağ Üniversitesi Tıp Fakültesi, Fiziksel Tıp ve Rehabilitasyon Anabilim Dalı, Bursa.

\begin{abstract}
ÖZET
Karpal tünel sendromu (KTS), en sık görülen tuzak nöropatisidir. Ellerde ağrı, uyuşma ve kuvvetsizlik gibi yakınmalarla karakterizedir. Fibromiyalji (FM) ise yaygın ağrının eşlik ettiği kronik kas iskelet sistemi hastalığıdır. Geniş semptom yelpazesi içinde parestezi yakınması sık görülmekte olup KTS ile karışabilmektedir. FM'li hastalarda KTS sıklığını araştıran az sayıda çalışma olup sonuçlar çelişkili bulunmuştur. Bu çalıșmada amaç, klinik olarak KTS ile uyumlu yakınmaları olup sinir ileti çalıșmalarında KTS saptanan ve saptanmayan iki grup arasında FM açısından farlılık olup olmadı̆̆ını araştırmaktır. Fiziksel Tıp ve Rehabilitasyon Polikliniği’ne başvuran ve KTS ön tanısı ile elektrofizyoloji laboratuvarına yönlendirilen kadın hastalar çalışmaya dahil edilmiştir. Tüm hastalara FM 2016 ACR tanı kriterleri uygulanmış ve Yaygın Ağrı İndeksi (YAI), Semptom Şiddet Skalası (SSS), Fibromiyalji Şiddet Skoru (FŞS) kaydedilmiştir. Hastalar elektrofizyolojik olarak KTS saptanan ve saptanmayan iki gruba ayrılarak sonuçlar karşılaştırılmıştır. Çalışmaya ellerde uyuşma yakınması olan ve sinir ileti çalıșması sonucunda $30 \mathrm{KTS}$ pozitif, $25 \mathrm{KTS}$ negatif hasta alındı. İki grup arasında yaşa ve beden kitle indeksine göre farklılık saptanmadı. KTS saptananların \%26,7'sinde, saptanmayanların \%24'ünde ACR 2016 kriterlerine göre FM saptanmış olup, iki grup arasında istatistiksel olarak anlamlı fark bulunmamıștı. YAİ, SSS ve FŞS incelendiğginde de gruplar arasında istatistiksel fark saptanmamıștır. Diğer yandan FM saptanan ve saptanmayan iki grup karșılasstırıldığında FM saptanmayan grupta median sinir ileti hızları anlamlı olarak daha yavas bulundu. Sonuç olarak, KTS hastalarında FM prevalansı yüksek bulunmuştur. FM olan ve olmayan KTS hastalarının median sinir iletim hızlarında anlamlı farklılıklar olduğundan, FM hastalarında KTS tanısı için elektrofizyolojik doğrulama önerilebilir.
\end{abstract}

Anahtar Kelimeler: Fibromiyalji. Karpal tünel sendromu. Sinir ileti çalışması.

The Frequency of Fibromyalgia in Patients Presenting with Symptoms of Carpal Tunnel Syndrome

\begin{abstract}
Carpal tunnel syndrome (CTS) is the most common entrapment neuropathy. It is characterized by complaints such as pain, numbness and weakness in the hands. Fibromyalgia (FM) is a chronic musculoskeletal disease accompanied by widespread pain. In a wide range of symptoms, complaints of paresthesia are common and can be confused with CTS. There are few studies investigating the frequency of CTS in patients with FM, and the results have been contradictory. The aim of this study is to investigate whether there is a difference in terms of FM between the electrophysiologically confirmed and not confirmed CTS patients. Female patients who admitted to the Physical Medicine and Rehabilitation Outpatient Clinic and were referred to the electrophysiology laboratory with a preliminary diagnosis of CTS were included in the study. FM 2016 ACR diagnostic criteria were applied to all patients and the Widespread Pain Index (WPI), Symptom Severity Scale (SSS), Fibromyalgia Severity Score (FSS) were recorded.As a result of the nerve conduction study, 30 CTS positive and 25 CTS negative patients were included in the study. There was no difference between the two groups according to age and body mass index. FM was diagnosed according to ACR 2016 criteria in $26.7 \%$ of those with CTS, and $24 \%$ of those without and there was no statistically significant difference between the two groups. No statistical difference was found between the groups according to WPI, SSS and FSS. On the other hand, when the two groups with and without FM were compared, the median nerve conduction velocities were significantly slower in the group without FM. As a result, the prevalence of FM is high in CTS patients. Since there are significant differences in the median nerve conduction velocities of CTS patients with and without FM, electrophysiological confirmation may be recommended for CTS diagnosis in FM patients.
\end{abstract}

Key Words: Fibromyalgia. Carpal tunnel syndrome. Nerve conduction study.

Geliş Tarihi: 29.Temmuz.2020

Kabul Tarihi: 18.Eylül.2020

* 27. Uluslararası Fiziksel Tıp ve Rehabilitasyon Kongresi'nde (17-21 Nisan 2019, Antalya) sözlü bildiri olarak sunulmuştur.

Dr. Şüheda ÖZÇAKIR

Bursa Uludağ Üniversitesi Tıp Fakültesi,

Fiziksel Tıp ve Rehabilitasyon Anabilim Dalı, Bursa.

Tel: 02242950821

E-posta: suheda@uludag.edu.tr

Yazarların ORCID ID Bilgisi:

Şüheda ÖZÇAKIR: 0000-0003-0851-3620
Karpal Tünel Sendromu (KTS), en sık görülen tuzak nöropatisidir ${ }^{1}$. Median sinirin el bileği düzeyinde osteofibröz kanaldan geçerken sıkışması sonucunda gelişir. Karpal tünel olarak bilinen bu kanal, bilek kemikleri, transvers karpal ligament, median sinir ve el parmak fleksör tendonları içerir. Ödem, tendon inflamasyonu, hormonal değişiklikler ve manuel aktivite, sinirin sıkışmasına katkıda bulunur ve üst ekstremitede ağrı ve uyuşmaya yol açar. Daha ciddi vakalarda, median sinir innervasyonlu kaslarda kuvvet kaybı gelişebilir. 


\section{Ş. Özçakır}

Ortalama 50 yaş kadınları daha sık etkilediği bilinse de bu veriler genellikle elektrofizyoloji laboratuvarlarına yapılan başvurulardan elde edilmiştir ${ }^{2,3}$. İsveç'te yapılan toplum bazlı bir çalışmada prevalansın erkek ve kadında benzer olduğu sonucuna varılmıştır (erkek:kadın oranı 1:1,4). Yaş ilerledikçe kadınlarda prevalans artmaktadır ve 65-74 yaşları arasında, görülme sıklığı erkeklere göre yaklaşık dört kat daha fazladır (sırasıyla \% 5,1 ve $\% \quad 1,3)^{4}$. Bilinen risk faktörleri arasında diabetes mellitus, menopoz, hipotiroidizm, obezite, artrit ve gebelik sayllabilir. Bazı antropometrik farklılıkların da KTS'ye neden olduğu bilinmektedir ${ }^{5}$. Detaylı bir öykü KTS tanısı koymada çok önemlidir. Hastalık başlangıcında olan intermittan noktürnal parestezi ve dizestezi yakınması zamanla sıklığını artırır ve gün içinde de devam eder. Daha da ileri aşamada aksonal hasar ile birlikte duyusal ve motor defisit gelişir. KTS de yakınmalar başlangiçta elde hakimdir ancak ileri dönemde ön kol, kol ya da omuza yayılım gösterebilir. Muayenede Tinel ve Phalen testleri sıklıkla kullanılmaktadır. Bu testler sıkışan median sinirin artmış duyarlılığını ortaya koyma ya da karpal tünelde pozisyonel basınç artışı ile parestezik yakınmaları ortaya çıkarmayı hedeflemektedir. Tanıda şüphe varsa ya da sinirin hasar derecesini ortaya koymak gerektiğinde duyusal ve motor sinir ileti çalışmaları yapılır. Tedavide öncelikle splintleme, fizik tedavi yöntemleri, lokal steroid enjeksiyonları gibi konservatif yöntemler tercih edilir. Konservatif tedavi ile semptomlar gerilemediğinde ya da ileri evre KTS varlığında karpal tünelin serbestleştirilmesine yönelik cerrahi tedavi uygulanır.

Fibromiyalji (FM), yaygın ve inatçı ağrı ile karakterize inflamatuar olmayan kronik kas iskelet sistemi hastalığıdır. Genel popülasyonda prevalans \%2-4 olup kadinlarda daha sik görülmektedir ${ }^{6}$. Etyolojisi henüz tam olarak aydınlatılamamış olmakla birlikte genetik ve çevresel faktörlerin yanında ağrıya karşı artmış santral sensisitizasyon ve azalmış endojen inhibisyon yanıt sorumlu tutulmaktadir ${ }^{7}$. Hastalık semptomatoloji açısından çok zengin olmakla birlikte objektif muayene bulgularının olmaması tanı ve tedavide sorunlara yol açmaktadır. Semptomlar arasında ağrı, yorgunluk, uyku bozuklukları, baş ağrısı, anksiyete, depresyon, sabah tutukluğu, ekstremitelerde uyuşma ve paresteziler, kuvvetsizlik, yumuşak doku şişliği, irritabl barsak ve dizüri sayılabilir. Tanıda ACR (American College of Rheumatology) 1990 kriterleri $^{8}$ yaygın ve kronik ağrının yanında bilateral 18 vücut bölgesinin 11'inde duyarlılık ararken 2010 kriterlerinde duyarlı nokta muayenesi kaldırılmıștır. 2010 kriterlerinde hasta sorgusu ile ortaya konabilen "yaygın ağrı indeksi (YAİ)" ve "semptom şiddet skalası (SSS)" getirilmitir 6 . YAİ değerlendirilirken hasta 19 vücut bölgesinde ağrısının olup olmadığını yanıtlar. İki bölümden oluşan SSS'nda ise hasta belirtilen semptomların varlığını ve şiddetini değerlendirir. $\mathrm{Bu}$ kriterler daha sonra $2011^{9}$ ve 2016' da $^{10}$ güncellenmiştir. FM tedavisinde hastanın eğitimi ve tedaviye katılımının sağlanması önemlidir. Egzersiz ve bilişsel-davranışsal tedavi yöntemleri de etkili bulunmuştur. FDA onaylı medikal tedavilerden serotonin-noradrenalin geri alım inhibitörlerinden duloksetin ve GABA analoğu anti-epileptik bir ilaç olan pregabalin sıklıkla kullanılmaktadır ${ }^{11}$.

Fibromiyalji hastalarında ekstremitelerde parestezi semptomları \%26-84 oranında görülmekte olup ayırıcı tanıda tuzak nöropatileri ile karışabilmektedir ${ }^{12}$. Konu ile ilgili yapılan çalışmalarda çelişkili sonuçlar bildirilmiştir. Fibromiyalji tanılı 50 hastanın kontrol grubu ile karşılaştırıldığı bir çalışmada parestezi ve duyusal yakınmalar FM grubunda anlamlı olarak daha fazla bulunmuștur. Elektrofizyolojik incelemede, gruplar arasında KTS tanısı açısından istatistiksel olarak anlamlı fark olmamakla birlikte FM grubunda $\% 10$, kontrol grubunda $\% 4$ oranında KTS saptanmıştır ${ }^{13}$. Ekstremitelerinde parestezi yakınması olan 17 FM hastasının sinir ileti çalışması kontrol grubu ile karşılaştırıldığında FM grubunda \%15, kontrol grubunda \%5,9 oranında KTS ile uyumlu sonuçlar elde edilmiş olup istatistiksel olarak anlamlı fark bulunmamıştır ${ }^{14}$. Bir başka çalışmada, 63 FM hastası kontrol grubu ile karşılaştırılmış, FM grubunda $\% 20,63$, kontrol grubunda $\% 2,82$ oranında KTS saptanmış olup sonuçlar istatistiksel olarak anlamlı bulunmuştur ${ }^{12}$

Biz de bu çalışmada klinik olarak KTS ön tanısı olan ve sinir ileti çalışmaları ile tanısı doğrulanan ya da reddedilen hastalar arasında FM açısından farlılık olup olmadığını araştırmayı hedefledik.

\section{Gereç ve Yöntem}

Bu çalışma Uludağ Üniversitesi Tıp Fakültesi Klinik Araştırmalar Etik Kurulu tarafından 25.03.2019 tarih ve 2019-6/12 sayılı kararla onaylanmıştır. Bursa Uludağ Üniversitesi Tıp Fakültesi Fiziksel Tıp ve Rehabilitasyon Poliklinikleri'ne ellerde uyuşma yakınması ile başvuran ve KTS klinik tanısı ile sinir ileti çalışması yapılan kadın hastalar çalışmaya alındı. Geçirilmiş el bilek kırı̆̆ı, inflamatuar romatizmal hastalık, hipotiroidizm gibi sekonder KTS nedeni olabilecek hastalık öyküsü olan hastalar çalışmaya alınmadı. Ayrıca nöropatiye neden olabilecek nörolojik hastalığı olan hastalar da çalışma dışında bırakıldı. Hastalar EMG cihazı veri tabanında kayıtlı bilgilerine göre bir yıl öncesine kadar retrospektif olarak çalışmaya alındı. Hastalar sinir ileti çalışma verilerine göre "KTS var" ve "KTS yok" olmak üzere iki gruba ayrıldı. Sinir ileti çalışmalarından median sinir duyusal tepe latansı $(\mathrm{msn})$ ve ileti hızı $(\mathrm{m} / \mathrm{sn})$ ile median motor sinir distal latansı(msn) ve ileti hızı (m/sn) kaydedildi. KTS sap- 


\section{KTS ve Fibromiyalji}

tan hastalar sinir ileti çalışmalarındaki verilere göre hafif (median duyusal sinir iletiminin uzaması ve/veya amplitüdünde düşme), orta (hafif KTS'ye ek olarak median motor sinir distal latansında uzama) ve ileri (sıklıkla median duyusal sinir potansiyelinin yokluğu ve median motor sinir amplitüd düşüklüğü) KTS olarak sinıflandirıldi.

Klinik olarak KTS tanısı olan ve elektrofizyolojik olarak tanısı doğrulanan ve doğrulanamayan bu iki grup hasta telefonla aranarak ACR 2016 FM tanı kriterlerine göre sorgulandılar ${ }^{15}$. Aşağıda belirtilen ilk 3 kriteri karşılayan hastalara Fibromiyalji tanısı konuldu: 1) yaygın ağrı indeksi $\geq 7$ ve semptom şiddet skalası $\geq 5$ veya yaygın ağrı indeksi $\geq 5$ ve semptom şiddet skalası $\geq 9$ 2) yaygın ağrı: 5 bölgenin 4 'ünde ağrı vardır. Çene, göğüs ve abdominal ağrıyı kapsamaz. 3) semptom süresi 3 ay ve daha uzundur. 4) Dişlama tanısı değildir. Diğ er hastalıkların varlığında tanı geçerlidir. Yaygın Ağrı İndeksinde (YAİ) 5 vücut alanı ve bu alanlarda toplam 19 bölge belirlenmiştir. Birinci bölge: sol üst (sol çene, sol omuz, sol kol, sol önkol), ikinci bölge: sağ üst (sağ çene, sağ omuz, sağ kol, sağ önkol), üçüncü bölge: sol alt (sol kalça, sol üst bacak, sol alt bacak) dördüncü bölge: sağ alt (sağ kalça, să̆ üst bacak, sağ alt bacak), beşinci bölge: (boyun, sirt, bel, göğüs, karın). Her bir bölgede var olan ağrı için bir puan verilir ve YAİ "0-19" arasında bir puan alır.

Semptom Şiddet Skalası (SŞS) iki bölümden oluşur. İlk bölümde hastanın son bir hafta içinde yaşadığ “yorgunluk", “dinlenmeden uyanma” ve "kognitif semptomlar" şiddetini 0-3 arasında puanlaması istenir. Buna göre hasta semptom şiddetini 0: yok, 1:hafif, 2:orta, 3: şiddetli olarak belirler. SŞS'nın ikinci bölümünde hasta son altı ayda yaşadığı "baş ağrısı", "alt karın bölgesinde ağrı veya kramp" ve "depresyon" varlığını yok: 0, ya da var:1 olarak yanıtlar. Buna göre SŞS toplamda "0-12" arasında kaydedilir.

YAİ ile SŞS skorları toplandığında ise Fibromiyalji Şiddet Skoru (FŞS) elde edilir.

\section{Biyoistatistiksel Analiz}

Çalışmanın analizleri SPSS (IBM Corp. Released 2012. IBM SPSS Statistics for Windows, Version 21.0. Armonk, NY: IBM Corp.) istatistiksel analiz programı kullanılarak yapılmıştır. Sürekli değişkenlerin normal dağılıma uygunluğu Shapiro Wilk testi ile incelenmiş olup test sonucuna göre gruplar arası karşılaştırmalarda Mann Whitney U testi, Bağımsız çift örneklem ttesti ve Ki-kare testi kullanılmıştır Sürekli değer alan değişkenler ortalama, standart sapma, medyan, min.max. değerleri ile birlikte verilmiştir. Sürekli değişkenlerin arasındaki ilişkileri incelemek amacıyla korelasyon analizi yapılmıştır. Çalışmada istatistiksel anlamlılık $\mathrm{p}<0,05$ olarak kabul edilmiştir.

\section{Bulgular}

Çalışmamıza klinik olarak KTS saptanan ve ayrıca elektrofizyolojik olarak tanısı doğrulanan 30 ve doğrulanmayan 25 hasta çalışmaya alındı. Her iki grubun yaş ve beden kitle indeksi (BKİ) verileri Tablo I'de verilmiştir. Elektrofizyolojik olarak KTS saptanan ve saptanmayan hastalar arasında FM varlığı açısından fark saptanmamıştır. Klinik olarak KTS varlığında $(\mathrm{n}=55)$ FM sıklığı \%25,45, Hem klinik hem elektrofizyolojik olarak KTS varlığında FM sıklığı \% 26 bulunmuştur (Tablo II). KTS saptanan ve saptanmayan gruplar YAI, SŞS ve FŞS açısından karşılaştırıld1ğında da gruplar arasında istatistiksel olarak anlamlı fark saptanmamıştır $(\mathrm{p}>0,05)$. Ayrıca hastalar "FM var" ve "FM yok" olarak iki gruba ayrılarak median duyusal ve motor sinir ileti çalışmaları açısından karşılaştırıldı. Buna göre FM saptanan hastalarda median duyusal ve motor sinirin ileti çalışmalarında istatistiksel olarak anlamlı farkl11ıklar saptand $1(\mathrm{p}<0,001)$ (Tablo III).

Tablo I. Hastaların yaş ve beden kitle indeksine (BKİ) göre dağılımı

\begin{tabular}{|l|c|c|}
\hline & $\begin{array}{c}\text { Yaş medyan (min- } \\
\text { maks) }\end{array}$ & BKi medyan (min-maks) \\
\hline KTS var $(\mathbf{n}=\mathbf{3 0})$ & $49,5(35-79)$ & $29,52(21,47-40,37)$ \\
\hline KTS yok $(\mathbf{n}=\mathbf{2 5})$ & $49(29-72)$ & $27,55(18,7-38,57)$ \\
\hline P değeri & 0,393 & 0,171 \\
\hline
\end{tabular}

KTS: Karpal tünel sendromu BKİ: beden kitle indeksi

Tablo II. Hastaların KTS ve Fibromiyalji varlığına göre dağılımı

\begin{tabular}{|c|c|c|c|}
\hline \multirow{2}{*}{ Fibromiyalji } & \multicolumn{2}{|c|}{ KTS } \\
\cline { 3 - 4 } & $\begin{array}{c}\text { Var } \\
\text { n (\%) }\end{array}$ & $8(26,7)$ & $6(24,0)$ \\
\cline { 2 - 4 } & $\begin{array}{c}\text { Yok } \\
\text { n (\%) }\end{array}$ & $22(\% 73)$ & $19(\% 76)$ \\
\hline \multicolumn{2}{|c|}{ P değeri } & \multicolumn{2}{|c|}{0,821} \\
\hline
\end{tabular}

KTS: Karpal tünel sendromu

Tablo III: Fibromiyalji saptanan ve saptanmayan hastalarda median sinir ileti sonuçlarının karşılaştırılması

\begin{tabular}{|c|c|c|c|c|}
\hline \multicolumn{2}{|c|}{ Fibromiyalji } & $\begin{array}{c}\text { Duyusal } \\
\text { latans (msn) }\end{array}$ & $\begin{array}{c}\text { Duyusal ileti } \\
\text { hızı (m/sn) }\end{array}$ & $\begin{array}{c}\text { Motor } \\
\text { latans } \\
\text { (msn) }\end{array}$ \\
\hline $\begin{array}{c}\text { Var } \\
\text { (n=14) }\end{array}$ & Medyan & 14 & 14 & 14 \\
& Min & 3 & 54,75 & 3,08 \\
& Maks & 2,50 & 21,80 & 2,85 \\
& $n$ & 41 & 63,40 & 7,70 \\
Yok & Medyan & 3,20 & 41 & 41 \\
$(\mathbf{n = 4 1 )}$ & Min & 2,20 & 49,10 & 3,70 \\
& Maks & 5,05 & 74,30 & 2,50 \\
& P & $<0,001$ & $<0,001$ & 12,5 \\
\hline
\end{tabular}




\section{Ş. Özçakır}

\section{Tartışma ve Sonuç}

$\mathrm{Bu}$ çalışmada, ellerinde uyuşma yakınması ile başvuran ve sinir ileti çalışmalarına göre KTS saptanan ve saptanmayan hastalar arasında fibromiyalji varlığ açısından fark saptanmamıştır. Diğer yandan KTS hastalarında fibromiyalji varlığı normal nüfusa göre daha sik bulunmuştur. Fibromiyalji olan ve olmayan iki grup karşılaştırıldığında ise median sinir ileti hızlarında ileri derecede anlamlı farklılık saptanmıştır.

FM ve KTS kadınlarda sık görülen iki hastalıktır. Genel popülasyonda prevalans FM için \%2 ve KTS için \%9,2 olarak bildirilmiștir ${ }^{16,17}$. İspanya'da yapılan bir çalışmada FM'li hastalarda KTS semptomlar1nın \%16 oranında gözlendiği, bunun genel popülasyondan daha yüksek olduğu ve altta yatan ortak mekanizmaların olabileceği bildirilmiştir ${ }^{18}$. FM'de KTS prevalansını Sarmer ve ark. ${ }^{13} \% 10$, Ersöz ve ark. ${ }^{14} \% 15$, Nacir ve ark. ${ }^{12} \% 20,6$, Silva ve ark. ${ }^{19} \% 19.5$ olarak rapor etmişlerdir. Bizim çalışmamızda FM hastaları değil, KTS hastaları alınmış ve bu grupta FM sıklığına bakılmıştır. Klinik olarak KTS varlığında FM sıklığ $1 \% 25,45$, hem klinik hem de elektrofizyolojik olarak KTS varlığında FM sıklığ 1 \%26 bulunmuştur. Elde edilen veriler literatür ile uyumlu olarak genel prevalansa göre her iki hastalığın birlikte görülme oranının yüksek olduğunu göstermektedir. $\mathrm{Bu}$ sıklık, FM ve KTS etyolojisinde benzerlikler olduğunu akla getirmektedir.

Çalışmamızda klinik olarak ellerde uyuşma yakınması olan tüm hastalar (n=55) FM varlığına göre iki gruba ayrıldığında, FM olmayan hastaların median sinir ileti sonuçları anlamlı düzeyde daha yavaş bulundu. $\mathrm{Bu}$ sonuçlar ekstremite parestezi yakınması sık görülen FM hastalarında klinik tanı yerine elektrofizyolojik değerlendirme sonrasında tanı koymak gerektiğini düşündürebilir.

Literatürde FM hastalarında ince lif nöropatisinin eşlik ettiği gösterilmiştir ${ }^{20,21}$. Bir başka çalışmada FM hastaları hem elektrofizyolojik olarak hem de sinir biyopsisi ile değerlendirilmişler ve hastaların \%90'ında demiyelinizan/aksonal sensorimotor polinöropati, \%63'ünde ise küçük lif nöropatisi saptanmıştır. Sonuç olarak FM hastalarında büyük lif nöropatisini saptamak ve ağrı patogenezini açıklayabilmek için elektrofizyolojik değerlendirmenin uygun olacağı sonucuna varılmıştır ${ }^{22}$.

$\mathrm{Bu}$ çalışmanın zayıf yönleri arasında hastaların geriye dönük olarak seçilmesi, klinik KTS muayene verilerinin yer almaması, FM kriterlerinin telefon aracılı̆̆ 1 ile sorgulanması ve nispeten az sayıda hastanın yer almas1 olarak sayılabilir.

Sonuç olarak, KTS hastalarında FM görülme sıklığı yüksektir. KTS semptomları gösteren FM hastalarının median sinir ileti hızlarında FM olmayanlara göre anlamlı farklılıklar olduğu için, FM hastalarında KTS tanısında elektrofizyolojik doğrulama önerilebilir. Sonuçlar bu iki hastalığın patogenezlerinde ortak noktaların olabileceği tanı ve tedavide dikkate alınmas1 gerektiğini düşündürmektedir.

\section{Teşekkür}

Dr. Cemre Güler, Dr. Burcu Sezer ve Dr. Gökhan Ocakoğlu'na veri toplama ve istatistiksel analizler konusundaki desteklerinden dolayı teşekkür ederim.

\section{Etik Kurul Onay Bilgisi:}

Onaylayan Kurul: Uludağ Üniversitesi Tıp Fakültesi Klinik Araștırmalar Etik Kurulu.

Onay Tarihi: 25.03 .2019

Karar No: 2019-6/12

\section{Kaynaklar}

1. Padua L, Coraci D, Erra C, Pazzaglia C, Paolasso I, Loreti C, et al. Carpal tunnel syndrome: clinical features, diagnosis, and management. The Lancet Neurology. 2016;15(12):1273-84.

2. Stevens JC. AAEM minimonograph \#26: the electrodiagnosis of carpal tunnel syndrome. American Association of Electrodiagnostic Medicine. Muscle \& nerve. 1997;20(12):1477-86.

3. Jablecki CK, Andary MT, So YT, Wilkins DE, Williams FH. Literature review of the usefulness of nerve conduction studies and electromyography for the evaluation of patients with carpal tunnel syndrome. AAEM Quality Assurance Committee. Muscle \& nerve. 1993;16(12):1392-414.

4. Atroshi I, Gummesson C, Johnsson R, Ornstein E, Ranstam J, Rosen I. Prevalence of carpal tunnel syndrome in a general population. Jama. 1999;282(2):153-8.

5. Ozcakir S, Sigirli D, Avsaroglu H. High wrist ratio is a risk factor for carpal tunnel syndrome. Clinical anatomy. 2018;31(5):698-701.

6. Wolfe F, Clauw DJ, Fitzcharles MA, Goldenberg DL, Katz RS, Mease P, et al. The American College of Rheumatology preliminary diagnostic criteria for fibromyalgia and measurement of symptom severity. Arthritis care \& research. 2010;62(5):600-10.

7. Galvez-Sanchez CM, Reyes Del Paso GA. Diagnostic Criteria for Fibromyalgia: Critical Review and Future Perspectives. Journal of clinical medicine. 2020;9(4).

8. Wolfe F, Smythe HA, Yunus MB, Bennett RM, Bombardier C, Goldenberg DL, et al. The American College of Rheumatology 1990 Criteria for the Classification of Fibromyalgia. Report of the Multicenter Criteria Committee. Arthritis and rheumatism. 1990;33(2):160-72.

9. Wolfe F, Clauw DJ, Fitzcharles MA, Goldenberg DL, Hauser W, Katz RS, et al. Fibromyalgia criteria and severity scales for clinical and epidemiological studies: a modification of the ACR Preliminary Diagnostic Criteria for Fibromyalgia. The Journal of rheumatology. 2011;38(6):1113-22.

10. Wolfe F, Clauw DJ, Fitzcharles MA, Goldenberg DL, Hauser W, Katz RL, et al. 2016 Revisions to the 2010/2011 fibromyalgia diagnostic criteria. Seminars in arthritis and rheumatism. 2016;46(3):319-29.

11. Okifuji A, Gao J, Bokat C, Hare BD. Management of fibromyalgia syndrome in 2016. Pain management. 2016;6(4):383-400.

12. Nacir B, Genc H, Duyur Cakit B, Karagoz A, Erdem HR. Evaluation of upper extremity nerve conduction velocities and 


\section{KTS ve Fibromiyalji}

the relationship between fibromyalgia and carpal tunnel syndrome. Archives of medical research. 2012;43(5):369-74.

13. Sarmer S, Yavuzer G, Kucukdeveci A, Ergin S. Prevalence of carpal tunnel syndrome in patients with fibromyalgia. Rheumatology international. 2002;22(2):68-70.

14. Ersoz M. Nerve conduction tests in patients with fibromyalgia: comparison with normal controls. Rheumatology international. 2003;23(4):166-70.

15. Yanmaz MN, Atar S, Bicer M. The reliability and validity of the Turkish version of fibromyalgia survey diagnostic criteria and symptom severity scale. Journal of back and musculoskeletal rehabilitation. 2016;29(2):287-93.

16. Wolfe F, Ross K, Anderson J, Russell IJ, Hebert L. The prevalence and characteristics of fibromyalgia in the general population. Arthritis and rheumatism. 1995;38(1):19-28.

17. de Krom MC, Knipschild PG, Kester AD, Thijs CT, Boekkooi PF, Spaans F. Carpal tunnel syndrome: prevalence in the general population. Journal of clinical epidemiology. 1992;45(4):373-6.
18. Perez-Ruiz F, Calabozo M, Alonso-Ruiz A, Herrero A, RuizLucea E, Otermin I. High prevalence of undetected carpal tunnel syndrome in patients with fibromyalgia syndrome. The Journal of rheumatology. 1995;22(3):501-4.

19. Silva FJ, Kanegusuku V, Bortoncello R, Skare T. Carpal tunnel syndrome and fibromyalgia. Acta reumatologica portuguesa. 2016;41(3):275-6.

20. Caro XJ, Winter EF. The Role and Importance of Small Fiber Neuropathy in Fibromyalgia Pain. Current pain and headache reports. 2015;19(12):55.

21. Hovaguimian A, Gibbons CH. Diagnosis and treatment of pain in small-fiber neuropathy. Current pain and headache reports. 2011;15(3):193-200.

22. Caro XJ, Galbraith RG, Winter EF. Evidence of peripheral large nerve involvement in fibromyalgia: a retrospective review of EMG and nerve conduction findings in 55 FM subjects. European journal of rheumatology. 2018;5(2):104-10. 
